\title{
ANALISIS PENGARUH LEBAR CELAH DAN JARAK ANTAR MAGNET TERHADAP DAYA DAN JARAK TEMPUH KAPAL PADA MHD CHANNEL TIPE HALL
}

\section{Analysis Air Gap Effect and Space Between Magnets on Ship Power and Distance Off Hall Type MHD Channel}

\author{
Setya Budi ${ }^{1}$, Triwahju Hardianto ${ }^{2}$, Widyono Hadi ${ }^{2}$ \\ ${ }^{1} J u r u s a n$ Teknik Elektro, Fakultas Teknik, Universitas Jember \\ ${ }^{2}$ Staf Pengajar Jurusan Teknik Elektro, Fakultas Teknik, Universitas Jember \\ JI. Kalimantan 37 Sumbersari, Jember, Jawa Timur, Indonesia 68121 \\ Email: setyabudi2198@gmail.com, triwahju@gmail.com,widyono.hadi1961@gmail.com
}

\begin{abstract}
ABSTRAK
Magnetohidrodinamika yang memanfaatkan medan magnetik serta cairan atau fluida yang mana untuk merubah menjadi energi gerak merupakan salah satu upaya pengganti penggerak kapal dari sistem penggerak propeler. Fokus dari penelitian ini yaitu untuk mengetahui pengaruh lebar celah channel terhadap daya dan kecepatan kapal pada channel type hall connection dengan sistem perubahan lebar celah channel, dari perubahan lebar celah channel tersebut akan meneliti pengaruh perubahan lebar celah channel dan jarak antar magnet terhadap kecepatan dan daya dorong prototype kapal MHD serta mencari nilai efisiensi daya dorong yang dikeluarkan dari keempat channel percobaan yang dibuat. Dari penelitian yang telah dilakukan ini dapat ditarik kesimpulan bahwa lebar celah dan jarak antar magnet sangat mempengaruhi terhadap daya dorong kapal yang dikeluarkan dan kecepatan jarak tempuh kapal. Sehingga dari empat percobaan tersebut didapatkan ukuran yang paling optimal untuk mendapatkan kecepatan dengan efisiensi daya dorong paling besar yakni saat menggunakan ukuran channel $120 \mathrm{~mm} \times 23 \mathrm{~mm} \times$ $25 \mathrm{~mm}$ dengan menggunakan ukuran magnet $12 \mathrm{~mm} \times 20 \mathrm{~mm} \times 10 \mathrm{~mm}$.
\end{abstract}

Kata kunci: Magnetohidrodinamika, Channel Hall, Lebar celah, Kecepatan, Daya dorong.

\section{ABSTRACT}

Magnetohydrodynamics that utilize magnetic fields and fluids or fluids which to convert into motion energy is one of the efforts to replace ship propulsion from propeller propulsion systems. The focus of this research is to determine the effect of channel gap width on the power and speed of the ship in the channel type hall connection with a channel gap change system, from the channel gap width change will examine the influence of channel gap width and distance between magnets on speed and thrust prototype ship MHD and look for the value of the efficiency of the thrust released from the four experimental channels created. From this research, it can be concluded that the gap width and the distance between magnets greatly affect the thrust of the ship issued and the speed of the ship's mileage. So from the four experiments obtained the most optimal size to get the speed with the greatest thrust efficiency that is when using a channel size of $12 \mathrm{~cm} \times 2.3 \mathrm{~cm} \times 2.5 \mathrm{~cm}$ by using a magnetic size of $12 \mathrm{~cm} \times 2 \mathrm{~cm} \times 10 \mathrm{~cm}$.

Key words: Magnetohydrodynamic, Channel Hall, Gap effect, Speed, Push power.

\section{PENDAHULUAN}

Penggunaan energi listrik untuk setiap tahunnya yang semakin meningkat menjadikan penggunaan energi harus digunakan dengan cerdas, konsumen dituntut dapat menggunakan energi listrik dengan bijak seperti mematikan peralatan elektronik saat tidak dipakai untuk mencegah pemborosan dalam penggunaanya. Para peneliti dan pembuat alat elektronik juga terus berupaya agar peralatan elektronik dapat digunakan dengan daya yang minimal dengan hasil yang maksimal. Efisiensi yang baik pada alat elektronik dapat mampu menekan penggunaan energi listrik yang tidak perlu karena rugi rugi daya.

Magnetohidrodinamika

yang menggunakan energi alternatif merupakan salah satu upaya pengganti penggerak kapal dari sistem penggerak propeler. Magnetohidrodinamika terdiri dari kata 
magneto yang berarti medan magnetik kemudian hydro yang memiliki arti cairan atau fluida, dan dynamic yang memiliki arti pergerakan. Menurut Tanoto mahasiswa teknik elektro Universitas Indonesia yang ditulis pada tahun 2009 mengatakan bahwa Magnetohidrodinamika (MHD) dapat diartikan sebagai suatu penghantaran dan pergerakan suatu fluida secara elektrik di dalam suatu medan magnetik. Fluida yang dimaksud dapat berupa plasma, logam cair, atau air garam.

Salah satu bagian utama dari magnetohidrodinamika adalah channel kapal yaitu sebagai tempat perpotongan medan magnet dengan arus listrik yang mana Channel kapal yang digunakan adalah type Hall connection dimana kedua elektrodanya kutub yang sama saling berhadapan. Dalam channel kapal terdapat magnet yang memiliki fungsi sangat penting, karena kapal magnetohidrodinamika bergerak akibat timbulnya gaya Lorentz, dimana arus listrik yang dikirimkan berpotongan dengan medan magnet di dalam air laut (plasma).

Penelitian sebelumnya yang telah dilakukan oleh Dwi Suputera Adi tahun 2015 yang berjudul "Pemanfaatan Magnetohidrodinamika Sebagai Energi Penggerak (Magnetic Propulsion)". pada penelitian kedua yang dilakukan oleh Nur Dwi Ratno tahun 2016 dengan mengangkat judul "Rancang Bangun Magnetohidrodinamika Sebagai Energi Penggerak Pada Kapal Dengan Menggunakan Tipe Kanal Diagonal Conducting Wall". Yang terbaru penelitian yang dilakukan oleh Muhammad Mawahib pada tahun 2017 dengan judul "Pemanfaatan Magnetohidrodinamika Sebagai Energi Penggerak Magnetik Pada Kapal Dengan Menggunakan Channel Tipe Hall Connection. Dari ketiga penelitian tersebut merupakan penelitian rancang bangun kapal MHD dengan menggunakan channel yang berbeda dari setiap penelitian. Parameter yang diambil dari penelitian ini adalah perbandingan dari konfigurasi channel yang berbeda dengan menggunakan satu ukuran channel dari setiap konfigurasi channel.

Dalam penelitian yang dilakukan oleh Muhammad Mawahib pada tahun 2017 dengan judul "Pemanfaatan Magnetohidrodinamika Sebagai Energi Penggerak Magnetik Pada Kapal Dengan Menggunakan Channel Tipe Hall Connection" dimana channel kapal hanya mengunakan dua ukuran yakni $12 \mathrm{~cm} \times 2,5 \mathrm{~cm}$ x $2,5 \mathrm{~cm}$ dan $12 \mathrm{~cm} \times 2,2 \mathrm{~cm} \times 1,5 \mathrm{~cm}$ dan magnet ukuran $9 \mathrm{~cm} \times 2,2 \mathrm{~cm} \times 1,5 \mathrm{~cm}$ dan $12 \mathrm{~cm} \times 2,2 \mathrm{~cm} \times 1,5 \mathrm{~cm}$ karena pada penelitian tersebut dilakukan penelitian untuk mengetahui pengaruh channel type hall connection terhadap tegangan dan arus pada kecepatan kapal dan kekuatan daya dorong yang dihasilkan kapal MHD dengan membandingkan kapal mengggunakan channel type faraday, tentu dalam penelitian tersebut masih dapat dikembangkan kembali, oleh karena itu dalam penelitian kali ini akan melanjutkan penelitian tersebut dengan meneliti pengaruh lebar celah channel terhadap daya dan kecepatan kapal pada channel type hall connection dengan sistem perubahan lebar celah channel yang kemudian secara tidak langsung akan mempengaruhi jarak antar magnet dan lebar ruang perpotongan medan magnet channel type hall connection, dari perubahan tersebut didalam penelitian ini akan diteliti pengaruh perubahan tersebut terhadap kecepatan dan daya yang dibutuhkan untuk menggerakkan kapal MHD.

\section{METODE PENELITIAN}

Penelitian "Pengaruh Lebar Celah dan Jarak Antar Magnet Pada Channel type hall connection Kapal MHD Terhadap Daya dan Jarak Tempuh Kapal " dilaksanakan pada bulan Desember 2019 sampai dengan Februari 2020 di Laboratorium Sistem Kendali, Fakultas Teknik, Universitas Jember di Jl. Slamet Riyadi no.62 Patrang, Jember.

\section{a. Blok Sistem}

Perancangan dan pembuatan alat ini dibuat sesuai dengan blok diagram pada Gambar 1. Dari baterai 24 volt menuju sensor tegangan lalu menuju mosfet sebagai penguat dan switch kemudian ke sensor arus lalu masuk ke dalam channel kapal. Sedangkan arduino berfungsi sebagai mikro yang mengatur besar kecil tegangan (PWM), menyimpan data penelitian pada data logger dan menampilkan data pada LCD.

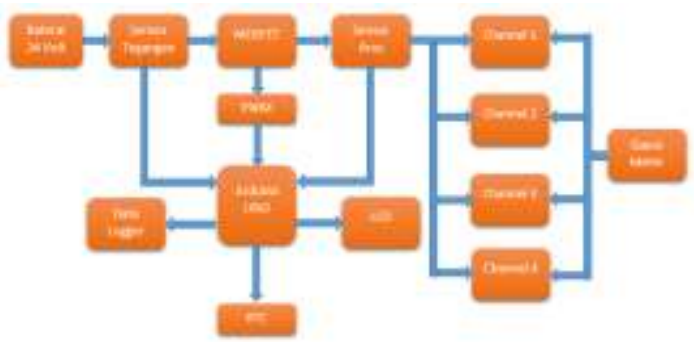

Gambar 1. Blok diagram system 
b. Flowchart

Pada Gambar 2 adalah flowchart dari sistem pengambilan data saat penelitian yang mana masukan yang diuji berupa empat channel uji dengan variasi lebar celah yang berbeda dan kemudian didapatkan nilai arus dan tegangan pada kapal kapal MHD pada saat kondisi berbebeban setelah itu dilakukan analisis perhitungan medan magnet, pengambilan data kecepatan kapal, perhitungan daya yang dikeluarkan, perhitungan daya dorong dan yang terakhir didapatkan nilai efisiensi daya pada empat channe/ uji.

c. Perhitungan Medan Magnet

$$
\begin{aligned}
& B=\frac{B r}{\pi}\left[\tan ^{-1}\left(\frac{w \cdot I}{2 \cdot I_{1} \sqrt{4 x_{1}^{2}+1^{2}+w^{2}}}\right)\right. \\
& -\tan ^{-1}\left(\frac{w_{1}}{2\left(x_{1}+t\right) \sqrt{4\left(x_{1}+t\right)^{2}+p^{2}+w^{2}}}\right) \\
& \left.+\tan ^{-1}\left(\frac{w \cdot l}{2 x_{x} \sqrt{4 x_{2}{ }^{2}+l^{2}+w^{2}}}\right)-\tan ^{-1}\left(\frac{w \cdot l}{d\left(x_{2}+t\right) \sqrt{4\left(x_{2}+t\right)^{2}+l^{2}+w^{2}}}\right)\right]
\end{aligned}
$$

(Internatinational Magnetic Solution, 2004) http://www.magneticsolutions.com.au/

Dimana:

$\mathrm{B}=$ Medan magnet (Gauss)

$\mathrm{Br}=$ Magnet sisa (Gauss)

$\mathrm{W}=$ Panjang magnet $(\mathrm{mm})$

$\mathrm{I}=$ lebar magnet $(\mathrm{mm})$

$\mathrm{t}=$ ketebalan magnet $(\mathrm{mm})$

$\mathrm{X} 1=$ jarak antar magnet dengan rumus

$(\mathrm{d} / 2+\mathrm{x}), \mathrm{d}$ adalah jarak sebenarnya $(\mathrm{mm})$

$\mathrm{X} 2$ = jarak antar magnet dengan rumus (d/2-

$\mathrm{x})$, d adalah jarak sebenarnya ( $\mathrm{mm}$ )

d. Perhitungan Kerapatan Daya Listrik

$$
P=j . E \text {. }
$$

(RonJ'LitcMord, 2003)

Dimana:

$\mathrm{P}=$ Kerapatan daya listrik channel (Watt)

$\mathrm{j}=$ Kerapatan arus listrik $\left(\mathrm{A} / \mathrm{m}^{2}\right)$

$\mathrm{E}=$ Kerapatan medan listrik $\left(\mathrm{Wb} / \mathrm{m}^{2}\right)$

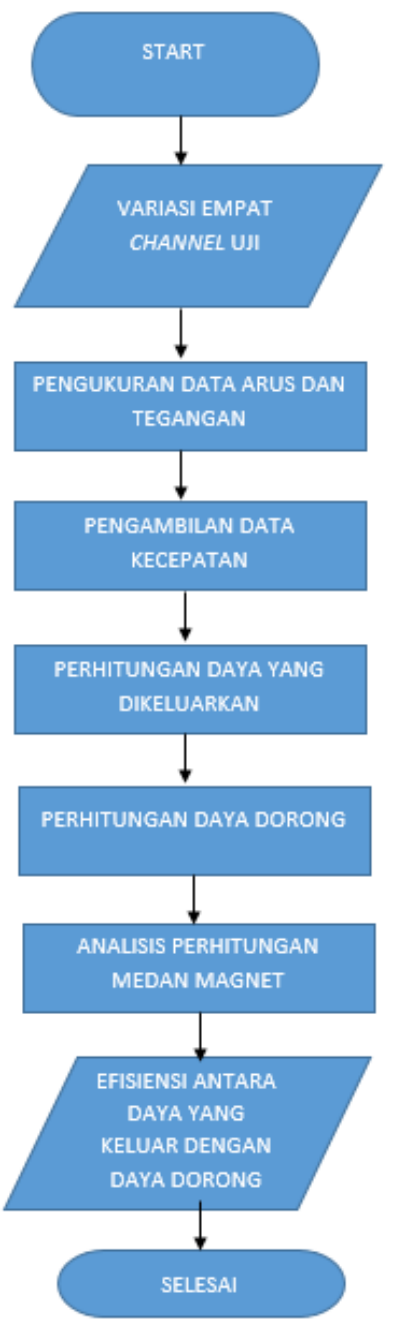

Gambar 2. Flowchart

e. Perhitungan Daya Dorong

$$
P p=u \cdot j \cdot B \text {. }
$$

(RonJ'LitcMord, 2003)

Dimana:

$\mathrm{Pp}=$ Daya dorong (Watt)

$\mathrm{u}=\operatorname{Kecepatan}(\mathrm{m} / \mathrm{s})$

$\mathrm{j}=$ Kerapatan arus listrik $\left(\mathrm{A} / \mathrm{m}^{2}\right)$

$B=$ Kerapatan medan magnet (Tesla)

f. Perhitungan Daya Disipasi

$$
P d=P-P p
$$

Dimana:

(RonJ'LitcMord, 2003)

$\mathrm{Pd}=$ Daya disipasi (Watt)

$\mathrm{P}=$ Kerapatan daya listrik channel (Watt)

$\mathrm{Pp}=$ Daya dorong komponen Lorentz (Watt)

g. Perhitungan Efisiensi Daya

$$
\eta_{\alpha}=\frac{u(j \times B)}{j \cdot s}
$$

(RonJ'LitcMord, 2003)

Dimana: 
$\eta_{a}=$ Efisiensi Daya

$\mathrm{j}=$ Kerapatan arus listrik $\left(\mathrm{A} / \mathrm{m}^{2}\right)$

$\mathrm{E}=$ Kerapatan medan listrik $\left(\mathrm{Wb} / \mathrm{m}^{2}\right)$

$\mathrm{u}=$ Kecepatan $(\mathrm{m} / \mathrm{s})$

$\mathrm{B}=$ Kerapatan medan magnet (Tesla)

\section{h. Desain Kapal}

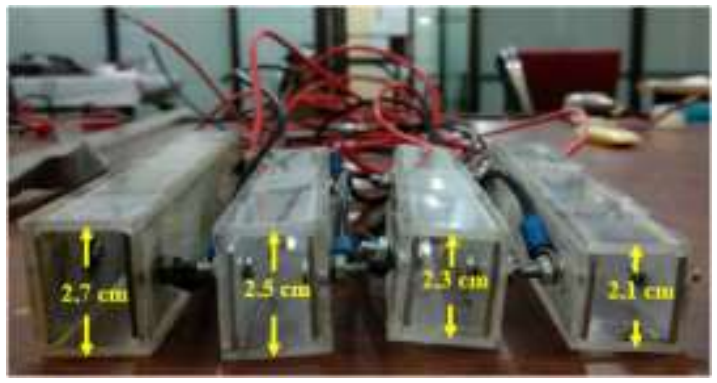

Gambar 3. Empat Channel uji

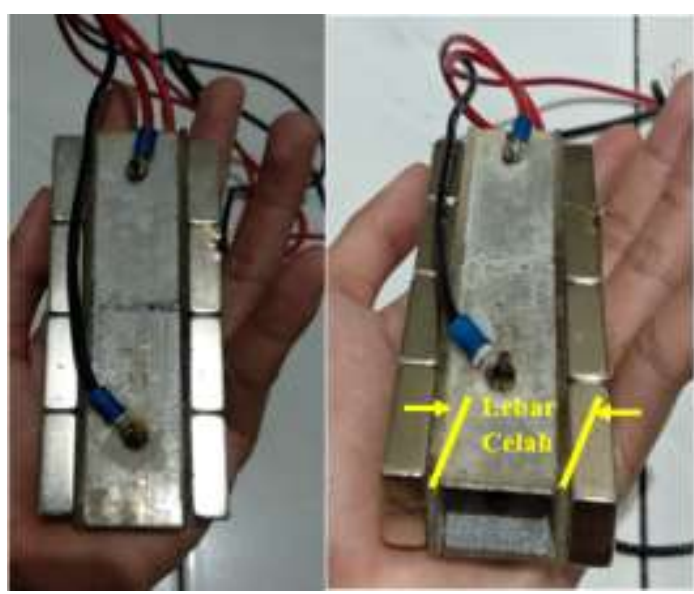

Gambar 4. Channel beserta megnet yang telah dipasang
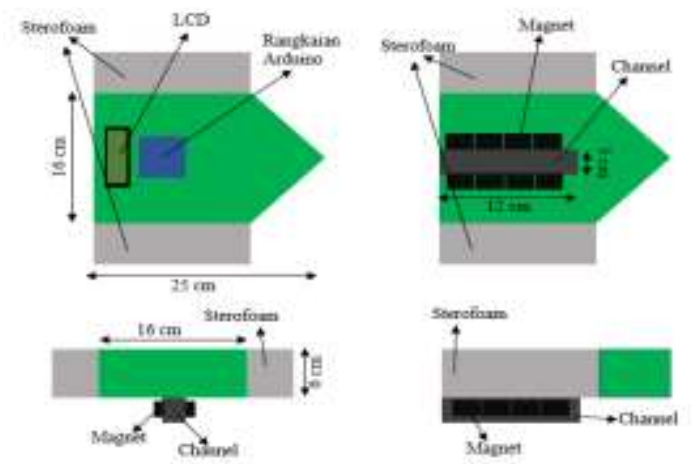

Gambar 5. Desain kapal MHD

\section{HASIL DAN PEMBAHASAN}

Pengujian utama dari penelitian yakni menganalisa nilai medan magnet yang ada pada channel uji kemudian mencari nilai tegangan, arus, dan kecepatan kapal saat pengujian untuk mendapatkan hasil daya yang dikeluarkan yang setelah itu didapatkan nilai efisiensi daya dorong dari setiap channel uji yang telah diteliti.

\section{a. Pengujian Pengujian Sensor Arus}

Dalam pengujian modul sensor arus AC712-20A-T memiliki fungsi untuk mengetahui keandalan sensor arus dalam membaca arus yang berada pada keluaran kapal MHD, keandalan sensor dapat diketahui melalui cara melihat nilai ADC yang dikeluarkan sensor saat membaca nilai arus yang terbaca dan nantinya nilai tersebut dikalibrasi dengan multimeter yang telah terkalibrasi agar nilai yang ditampilkan sensor arus dengan multimeter dapat sama dan memiliki error yang kecil.

Tabel 2 Pengujian kalibrasi sensor arus

\begin{tabular}{|c|c|}
\hline Arus & ADC sensor \\
\hline 0,1 & 1,28 \\
\hline 0,2 & 2,56 \\
\hline 0,3 & 3,85 \\
\hline 0,4 & 5,13 \\
\hline 0,5 & 6,42 \\
\hline 0,6 & 7,70 \\
\hline 0,7 & 8,99 \\
\hline 0,8 & 10,27 \\
\hline 0,9 & 11,56 \\
\hline 1,0 & 12,84 \\
\hline
\end{tabular}

\section{b. Pengujian Sensor Tegangan}

Penggunaan sensor tegangan digunakan untuk mengukur tegangan masukan dari baterai yang nantinya data pembacaan sensor tegangan akan dibaca setiap detiknya dan dikirim atau disimpan ke data logger untuk direkapitulasi bersama pembacaan sensor yang lain dalam satu waktu yang bersamaan. Tabel 3 Pengujian Sensor Tegangan.

c. Analisisa Kerapan Medan Magnet

Terhadap Dimensi Lebar Celah

Dalam analisa kerapatan medan magnet terhadap dimensi lebar celah channel untuk mengetahui pengaruh lebar celah channel yang berbeda beda terhadap kerapatan medan magnet, yakni dengan menggunakan variasi 4 buah macam dimensi lebar celah channel. Dibawah ini merupakan hasil perhitungan kerapatan medan magnet dengan lebar celah yang berbeda-beda. 
Tabel 3 Hasil pengujian Sensor Tegangan dengan Multimeter

\begin{tabular}{|c|c|}
\hline Multimeter (V) & Sensor Tegangan (V) \\
\hline 6,06 & 6,03 \\
\hline 7,10 & 7,20 \\
\hline 8,10 & 8,35 \\
\hline 9,80 & 9,50 \\
\hline 10,07 & 10,61 \\
\hline 11,25 & 11,98 \\
\hline 12,10 & 12,96 \\
\hline 13,27 & 14,38 \\
\hline 14,41 & 15,60 \\
\hline 15,40 & 16,73 \\
\hline 17,15 & 18,76 \\
\hline 18,35 & 20,12 \\
\hline 19,01 & 20,86 \\
\hline 20,20 & 22,25 \\
\hline 21,00 & 23,00 \\
\hline 22,00 & 24,00 \\
\hline 23,00 & 24,00 \\
\hline 24,00 & 24,00 \\
\hline & \\
\hline
\end{tabular}

Tabel 4 Dimensi megnet dan kerapatan medan magnet

\begin{tabular}{|l|c|}
\hline Dimensi celah channel & $\begin{array}{c}\text { Kerapatan Medan } \\
\text { Magnet }\end{array}$ \\
\hline $120 \mathrm{~mm} \times 27 \mathrm{~mm} \times 25 \mathrm{~mm}$ & $0,2385629 T$. \\
\hline $120 \mathrm{~mm} \times 25 \mathrm{~mm} \times 25 \mathrm{~mm}$ & $0,2435001595 \mathrm{~T}$ \\
\hline $120 \mathrm{~mm} \times 23 \mathrm{~mm} \times 25 \mathrm{~mm}$ & $0,2491781535 \mathrm{~T}$ \\
\hline $120 \mathrm{~mm} \times 21 \mathrm{~mm} \times 25 \mathrm{~mm}$ & $0,2558205532 T$ \\
\hline
\end{tabular}

Dari tabel 4 terlihat bahwa lebar celah channel berpengaruh terhadap kerapatan medan magnet. Ketika ukuran channel yakni $120 \mathrm{~mm} \times 27 \mathrm{~mm} \times 25 \mathrm{~mm}$ didapatkan nilai kerapatan medan magnet sebesar $0,2385629 T$, kemudian saat ukuran channel sebesar $120 \mathrm{~mm} \times 25 \mathrm{~mm} \times 25 \mathrm{~mm}$ nilai kerapatan medan magnet yang didapatkan sebesar 0,2435001595 $T$, setelah itu percobaan yang ketiga menggunakan ukuran channel sebesar $120 \mathrm{~mm} \times 23 \mathrm{~mm} \times 25 \mathrm{~mm}$ didapatkan nilai kerapatan medan magnet sebesar 0,2491781535 $T$, dan percobaan ukuran channel terakhir yakni ukuran $120 \mathrm{~mm}$ x $21 \mathrm{~mm} \times 25 \mathrm{~mm}$ yang menghasilkan nilai kerapatan medan magnet sebesar 0,2558205532 T.

\section{d. Pengujian Kapal Magnetohidrodinamika}

Dari pengujian celah channel tipe hall conection yang telah dilakukan dapat dilihat bahwa nilai kecepatan kapal saat menempuh jarak $30 \mathrm{~cm}$ dengan menggunakan tegangan yang sama yakni 24 volt memiliki waktu tempuh yang berbeda-beda. Pada saat penggunaan channel dengan ukuran $120 \mathrm{~mm}$ $x 27 \mathrm{~mm} \times 25 \mathrm{~mm}$ waktu yang diperlukan untuk mencapai jarak $30 \mathrm{~cm}$ adalah 20 detik menghasilkan kecepatan $0,015 \mathrm{~m} / \mathrm{s}$, dan saat channel diganti menggunakan channel ukuran $120 \mathrm{~mm} \times 25 \mathrm{~mm} \times 25 \mathrm{~mm}$ waktu yang diperlukan juga berubah menjadi 18 detik dalam jarak tempuh $30 \mathrm{~cm}$ menghasilkan kecepatan $0,01666 \mathrm{~m} / \mathrm{s}$. Setelah itu ketika ukuran channel diganti menjadi $120 \mathrm{~mm} x$ $23 \mathrm{~mm} \times 25 \mathrm{~mm}$ waktu yang dibutukan untuk menumpuh jarak $30 \mathrm{~cm}$ juga ikut berubah yakni 15,5 detik menghasilkan kecepatan sebesar $0,0193548 \mathrm{~m} / \mathrm{s}$, kemudian terakhir percobaan keempat menggunakan channel berukuran $120 \mathrm{~mm} \times 21 \mathrm{~mm} \times 25 \mathrm{~mm}$ yang dapat menempuh jarak $30 \mathrm{~cm}$ dengan waktu 20 detik yang menghasilkan kecepatan sebesar $0,015 \mathrm{~m} / \mathrm{s}$.

Pada pengukuran nilai arus selalu berubah-ubah pada setiap channel, nilai arus selalu berubah terjadi karena ukuran channel yang berbeda serta nilai arus yang cenderung terus menurun nilainya dikarenakan daya baterai terus menurun saat pemakaian. Pada saat ukuran channel $120 \mathrm{~mm} \times 27 \mathrm{~mm} \times 25 \mathrm{~mm}$ arus rata rata yang dihasilkan adalah sebesar 6,35 A, ketika ukuran channel diganti menjadi $120 \mathrm{~mm} \times 25 \mathrm{~mm} \times 25 \mathrm{~mm}$ nilai arus tetap yakni 6,35 A, dan saat ukuran channel kembali dirubah menjadi $120 \mathrm{~mm} \times 23 \mathrm{~mm} \times 25 \mathrm{~mm}$ nilai rata rata arus juga ikut naik yakni 7,30 A, kemudian percobaan keempat saat menggunakan ukuran $120 \mathrm{~mm} \times 21 \mathrm{~mm} \times$ $25 \mathrm{~mm}$ nilai arus juga semakin besar yakni $8,12 \mathrm{~A}$. 
Tabel 5 Pengaruh perubahan lebar celah channel dan jarak antar magnet

\begin{tabular}{|c|c|c|c|c|c|c|c|c|}
\hline $\begin{array}{c}\text { Ukuran } \\
\text { Channel(mm) }\end{array}$ & $\begin{array}{c}\text { Tegangan } \\
(\mathbf{V})\end{array}$ & $\begin{array}{c}\text { Arus } \\
(\mathbf{A})\end{array}$ & $\begin{array}{c}\text { Medan } \\
\text { Magnet (T) }\end{array}$ & $\begin{array}{c}\text { Kecepatan } \\
\text { (m/s) }\end{array}$ & $\begin{array}{c}\text { Daya P } \\
\text { (Watt) }\end{array}$ & $\begin{array}{c}\text { Daya Pd } \\
\text { (Watt) }\end{array}$ & $\begin{array}{c}\text { Daya Pp } \\
\text { (Watt) }\end{array}$ & $\begin{array}{c}\text { Efisiensi } \\
\text { (\%) }\end{array}$ \\
\hline $\begin{array}{c}120 \mathrm{~mm} \times 27 \mathrm{~mm} \\
\times 25 \mathrm{~mm}\end{array}$ & $23,87 \mathrm{~V}$ & 6,35 & 0,2385629 & 0,015 & 189,468 & 182,45 & 7,01 & 3,70 \\
\hline $\begin{array}{c}120 \mathrm{~mm} \times 25 \mathrm{~mm} \\
\times 25 \mathrm{~mm}\end{array}$ & $23,87 \mathrm{~V}$ & 6,35 & 0,2435001595 & 0,01666 & 189,468 & 180,88 & 8,5867 & 4,53 \\
\hline $\begin{array}{c}120 \mathrm{~mm} \times 23 \mathrm{~mm} \\
\times 25 \mathrm{~mm}\end{array}$ & $23,87 \mathrm{~V}$ & 7,30 & 0,2491781535 & 0,0193548 & 217,8 & 205,04 & 12,75 & 5,59 \\
\hline $\begin{array}{c}120 \mathrm{~mm} \times 21 \mathrm{~mm} \\
\times 25 \mathrm{~mm}\end{array}$ & $23,65 \mathrm{~V}$ & 8,12 & 0,2558205532 & 0,015 & 240 & 227,635 & 12,3646 & 5,15 \\
\hline
\end{tabular}

Daya disipasi yang dihasilkan pada empat channel yang berbeda lebar celahnya terlihat berbeda, ketika celah channel yang diuji adalah berukuran $120 \mathrm{~mm} \times 27 \mathrm{~mm} \times$ $25 \mathrm{~mm}$ menghasilkan daya sebesar 182,45 Watt, saat percobaan kedua menggunakan channel berukuran $120 \mathrm{~mm} \times 25 \mathrm{~mm} \times 25 \mathrm{~mm}$ dimana menghasilkan daya sebesar 180,88 Watt, setelah itu percobaan ketiga menggunakan channel yang berukuran $120 \mathrm{~mm} \times 23 \mathrm{~mm} \times 25 \mathrm{~mm}$ menghasilkan nilai daya sebesar 205,04 Watt, dan percobaan keempat menggunakan channel dengan ukuran paling kecil untuk lebar celahya yaitu $120 \mathrm{~mm} \times 21 \mathrm{~mm} \times 25 \mathrm{~mm}$ yang mengahasilkan daya sebesar 227,635 Watt.

Efisiensi yang didapatkan dari panelitian pengaruh lebar celah dan jarak antar magnet juga berbeda beda pada setiap pengujian channel dimana ketika ukuran channel $120 \mathrm{~mm} \times 27 \mathrm{~mm} \times 25 \mathrm{~mm}$ efisiensi yang dihasilkan yaitu sebesar $3,70 \%$, kemudian saat channel berukuran $120 \mathrm{~mm} x$ $25 \mathrm{~mm} \times 25 \mathrm{~mm}$ efisiensi yang dihasilkan yaitu sebesar $4,53 \%$, ketika ukuran channel dirubah menjadi $120 \mathrm{~mm} \times 23 \mathrm{~mm} \times 25 \mathrm{~mm}$ maka nilai efisiensi juga ikut berubah yakni sebesar $5,59 \%$, dan yang terakhir saat ukuran channel yang digunakan berukuran $120 \mathrm{~mm} \times 21 \mathrm{~mm} \times 25 \mathrm{~mm}$ maka nilai efisiensi yang dihasikal pada channel tersebut adalah $5,15 \%$.

Dari penelitian analisa pengaruh lebar celah dan jarak antar magnet terhadap daya dorong dan kecepatan kapal MHD channel tipe hall yang telah dilakukan ini, dapat diambil beberapa kesimpulan diantaranya adalah nilai rata rata arus yang semakin besar ketika lebar celah channel semakin kecil yang mana nilai arus terbesar terjadi saat channel berukuran $120 \mathrm{~mm} \times 21 \mathrm{~mm} \times$ $25 \mathrm{~mm}$ dengan arus rata rata $8,12 \mathrm{~A}$. Kemudian kecepatan kapal tercepat untuk menempuh jarak $30 \mathrm{~cm}$ adalah ketika channel yang digunakan berukuran $12 \mathrm{~mm} \times 23 \mathrm{~mm} \times$ $25 \mathrm{~mm}$ yang dapat menempuh dengan kecepatan $0,0193548 \mathrm{~m} / \mathrm{s}$, setelah itu dari penelitian ini juga didapatkan nilai daya dorong yang dikeluarkan terbesar ketika ukuran channel yang terkecil dari penelitian ini yakni $120 \mathrm{~mm} \times 21 \mathrm{~mm} \times 25 \mathrm{~mm}$ yang menghasilkan daya sebesar 227,635 Watt, akan tetapi nilai efisiensi yang terbesar terjadi saat menggunakan channel ukuran $120 \mathrm{~mm} x$ $23 \mathrm{~mm} \times 25 \mathrm{~mm}$ dengan efisiensi sebesar $5,59 \%$. Dari beberapa kesimpulan yang telah didapatkan maka dapat ditarik kesimpulan secara keseluruhan bahwa lebar celah dan jarak antar magnet sangat mempengaruhi terhadap daya dorong kapal yang dikeluarkan dan kecepatan jarak tempuh kapal. Sehingga dari empat percobaan tersebut didapatkan ukuran yang paling optimal untuk mendapatkan kecepatan dengan efisiensi daya dorong paling besar yakni saat menggunakan ukuran channel $120 \mathrm{~mm} x$ $23 \mathrm{~mm} \times 25 \mathrm{~mm}$ dengan menggunakan ukuran magnet $120 \mathrm{~mm} \times 20 \mathrm{~mm} \times 10 \mathrm{~mm}$.

\section{KESIMPULAN}

Nilai rata rata arus semakin besar ketika lebar celah channel semakin kecil. Nilai arus terbesar terjadi saat channel berukuran $120 \mathrm{~mm} \times 21 \mathrm{~mm} \times 25 \mathrm{~mm}$ dengan arus rata rata $8,12 \mathrm{~A}$.. Selanjutnya Kecepatan kapal tercepat untuk menempuh jarak $30 \mathrm{~cm}$ adalah ketika channel yang digunakan berukuran $120 \mathrm{~mm}$ x $23 \mathrm{~mm} \times$ $25 \mathrm{~mm}$ yang dapat menempuh dengan kecepatan $0,0193548 \mathrm{~m} / \mathrm{s}$. Sedangkan nilai daya disipasi yang dikeluarkan yang paling besar yaitu ketika saat menggunakan ukuran channel yang terkecil dari penelitian ini yakni $120 \mathrm{~mm} \times 21 \mathrm{~mm} \times 25 \mathrm{~mm}$ yang menghasilkan daya sebesar 227,635 Watt.

Nilai daya dorong yang paling besar dihasilkan yakni saat menggunakan channel ukuran $120 \mathrm{~mm} \times 23 \mathrm{~mm} \times 25 \mathrm{~mm}$ 
dengan daya 12,75 Watt. Dengan Nilai efisiensi daya dorong yang terbesar terjadi saat menggunakan channel ukuran $120 \mathrm{~mm}$ $\times 23 \mathrm{~mm} \times 25 \mathrm{~mm}$ dengan efisiensi sebesar $5,59 \%$. Hasil secara menyeluruh memperlihatkan lebar celah dan jarak antar magnet sangat mempengaruhi terhadap daya dorong kapal yang dikeluarkan dan kecepatan jarak tempuh kapal. Sehingga dari empat percobaan tersebut didapatkan ukuran yang paling optimal untuk mendapatkan kecepatan dengan efisiensi daya dorong paling besar yakni saat menggunakan ukuran channel $120 \mathrm{~mm} x$ $23 \mathrm{~mm} \times 25 \mathrm{~mm}$ dengan menggunakan ukuran magnet $120 \mathrm{~mm} \times 20 \mathrm{~mm} \times 10 \mathrm{~mm}$.

\section{SARAN}

Rekomendasi untuk penelitian selanjutnya diantaranya terkait dengan bahan kapal, magnet, kapasitas baterai yang digunakan. Bahan kapal perlu dibuat lebih ringan untuk memperkecil beban, magnet yang digunakan perlu menggunakan magnet yang lebih besar agar menghasilkan medan magnet yang lebih kuat, kapasitas baterai yang digunakan lebih besar, karena arus yang keluar dari penelitian ini mencapai 9A. Selain itu perlunya penambahan navigasi kapal agar kapal magnetohidrodinamika lebih mudah saat pengendalian arah, .perbaikan desain prototype kapal dan perhitungan berat kapal untuk menyerupai bentuk kapal asli dan penelitian lebih lanjut untuk mengetahui hubungan torsi dan kuat medan pada kapal.

\section{REFERENSI}

[1] M. Abbasi, D. D. Ganji, and M. T. Rahni, "MHD flow in a channel using new combination of order of magnitude technique and HPM," Teh. Vjesn., vol. 21, no. 2, pp. 317-321, 2014.

[2] L. Conference and R. J. Litchford, "Perfomance Theory of Diogonal Conducting Wall MHD Accelerators" . AIAA-2003-4284," no. June, 2003.

[3] M. Mawahib, "Pemanfaatan Magnetohidrodinamika Sebagai Energi Penggerak Magnetik Pada Kapal Dengan Menggunakan Channel Tipe Hall Connection, Repository UNEJ, 2017.

[4] T. Hardianto, "Pandangan penelitian tentang generator dan akselerator magnetohidrodinamika", 2014.

[5] T. Hardianto, M.N.Kustanto, "Penentuan Posisi Sudut Channel Diagonal Generator Magnetohidrodinamika Untuk Mendapatkan Daya Listrik Optimal”, Laporan Penelitian Fundamental Tahun 2010 , DIPA Universitas Jember, 2011.

[6] T. F. Lin, J. B. Gilbert, and G. D. Roy, "Analyses of magnetohydrodynamic propulsion with seawater for underwater vehicles," J. Propuls. Power, vol. 7, no. 6, pp. 1081-1083, 1991.

[7] P. Magnetohidrodinamika, S. Energi, D. W. I. S. Adi, J. T. Elektro, F. Teknik, and U. Jember, "Pada kapal," 2015.

[8] Y. Megantara, M. W. Abdul, G. Octavia, O. Citra, M. Firdausul, A. Bryan, H. Soelaiman, and T. Hardianto, "SEBAGAI ENERGI RAMAH LINGKUNGAN PADA KAPAL," pp. 4-8.

[9] N. Sakamoto, J. Kondo, and N. Harada, "Computational study of MHD accelerator," Collect. Tech. Pap. - 37th AIAA Plasmadynamics Lasers Conf., vol. 1, no. June, pp. 60-73, 2006.

[10] T. Hardianto, M.N.Kustanto, "Penentuan Posisi Sudut Channel Diagonal Generator Magnetohidrodinamika Untuk Mendapatkan Daya Listrik Optimal" Penelitian Fundamental Tahun 2010, DIPA Universitas Jember 2010. 